Journal of Hospital Librarianship, Vol. 1, No. 4 2001, pp. 17-30.

Print ISSN: 1532-3269 Online ISSN:1532-3277

DOI: 10.1300/J186v01n04_02

http://taylorandfrancis.com/

http://www.informaworld.com/smpp/title $\sim$ content=t792306866 db=all

http://www.informaworld.com/openurl?genre=article\&issn=1532-3269\&volume $=1 \&$ issue $=4 \&$ spage $=17$

(C) 2001 by TheHaworth Press Inc. All rights reserved.

\title{
The Conflict Between Professional Ethics and the Ethics of the Institution
}

\section{Sarah Anne Murphy}

Sarah Anne Murphy is Head of the Veterinary Medical Library, The Ohio State University. She was previously Librarian at the Hardymon Medical Library, Ohio State University Hospitals East in Columbus, OH.

This article is based on a presentation at the Midwest Chapter/MLA, Cincinnati, OH, September 22-26, 2000.

\begin{abstract}
Hospital librarians face complex ethical challenges complicated by obligations to the library profession and the institutions they serve. Few articles have specifically addressed ethical conduct for hospital librarians. Thus when situations causing conflicts between professional ethics and the ethics of the institution arise, hospital librarians are ill prepared to resolve the enduring question: To whom do I assign my loyalties: the profession or the institution by which I am employed?

This article attempts to remedy this situation by examining the multidisciplinary field of professional ethics research. The discussion is organized into three thoughts/concepts: Conflicting Ethics; Professional Ethics; and Ethics, Professional Education and Professional Codes.
\end{abstract}

\section{INTRODUCTION}

Competition dominates the health care industry today. As reimbursement from Medicare and other insurance payers continues to dwindle, hospital administrators must scrutinize the financial worth of each department. Hospital libraries are particularly vulnerable since it is difficult to demonstrate the financial relevance of library services to patient care. To survive in the cutthroat hospital environment hospital librarians must adopt business strategies to their profession. This creates conflicting ethical issues. While hospital librarians support the ethical values of the profession, they also have an ethical obligation to their employer. Questions arise with regard to which ethical obligations should take precedence. Should hospital librarians support the competitive agendas of their individual institutions or function for the collective good of society?

The fundamental tenet of most library discussions on ethics is access to information. This tenet is supported by Article 19 of the Universal Declaration of Human Rights: "Everyone has the right to freedom of opinion and expression; this right includes freedom to hold opinions without interference and to seek, receive and impart information and ideas through any media and regardless of frontiers" (1). The Medical Library Association promotes access in its Code of Ethics for Health Sciences Librarianship stating: "The health sciences librarian promotes access to health information for all and creates and maintains conditions of freedom of inquiry, thought, and expression that facilitate informed health care decisions" (2). The American Library Association reinforces these views for hospital librarians in its Code of Ethics, Freedom to Read Statement, and Library Bill of Rights (3-5).

Regardless, access to information is threatened in today's health care environment as hospital librarians must adopt an entrepreneurial role. Considerations on such issues as whether 
to charge for services no longer cover the library's ability to improve access for all health care professionals. Decisions, instead, are focused on the library's ability to improve access for certain individuals or institutions whose access will result in a positive bottom line for the hospital. In other words, hospital librarians are functioning to "keep the physicians happy" (6).

Few researchers have addressed the conflicts between professional ethics and the ethics of the institution as it relates to the hospital library setting. This research void is surprising as ethics in health sciences librarianship significantly impact patient care. The Rochester study showed library information positively influences physician diagnosis and choice of tests, treatments and drugs. Such information enables physicians to avoid adverse events and reduce length of stay (7). Other studies produced similar results $(8,9)$. Thus, the hospital librarian indeed holds a crucial role within the hospital promoting quality patient care and improving patient outcomes. Issues relating to confidentiality and privacy, fees, access to information, level of service, professional competence and integrity, and censorship must be resolved both professionally and ethically within the context of the organization in which they work.

Hospital librarians, however, hold dual identities (10). As special librarians, hospital librarians work within organizations that have their own corporate culture, priorities and values. They grapple with the notion of whether their duty is first to the hospital or to the profession. Preer offers an insightful analogy of this predicament: "Does a company doctor think of himself (or herself) as an employee first and a doctor second? Is the special librarian more like the company doctor, with particular expertise and an independent set of professional standards, or the company clerk, ready to follow corporate rules?" (10).

This analogy exposes a weakness in professional library ethics which makes it difficult for hospital librarians to keep ethical duties to the profession and ethical duties to employers separate and distinct. The company physician is compelled to resolve ethical dilemmas within the context of the profession or risk legal repercussions or discipline by peers. His ethics are both codified and enforced. Librarian's professional ethics are codified; however, there are no mechanisms which require librarians to accept these ethics, and consequently there are no means to enforce adherence. This causes difficulty for librarians whose employers are not librarians and fosters an environment for conflict. The librarian must communicate and work with administrators who have little or no knowledge of library ethics and subsequent responsibilities to users.

Whose ethics should prevail: the hospital's or the hospital librarian's? Professional library literature skirts this issue. An abundance of books and articles on special libraries exists. Unfortunately, these items tend to address the strategies for and importance of enhancing the visibility of the special library: promoting its services; proving its worth within the organization, obtaining sufficient resources and staff, and obtaining a strategic position on the organizational chart (10). There is no doubt that these issues are essential for effective service within the special library. It is of concern, however, that little of what is published addresses ethical conduct for special librarians.

Research regarding professional ethics is especially sparse in non-traditional library settings. Thus, hospital librarians must sort through their ethical dilemmas with little or no guidance. This article attempts to remedy this situation by examining the multidisciplinary field of professional ethics research. Hospital librarians, especially, require an understanding of professional ethics to address ethical questions which challenge both their professional ethics and the ethics of the institution they serve. They should have a stronger knowledge of professional ethics and the excuses which make them irrelevant. Hospital librarians should be better equipped 
to eliminate or resolve conflicts between professional ethics and the ethics of the institution they serve Armed with a firm foundation in professional ethics, hospital librarians are better equipped to resolve the enduring question: "To whom do I assign my loyalties: the profession or the institution by which I am employed?" It is the author's hope that hospital librarians will be stimulated to discuss professional ethics with colleagues and to publish results.

This discussion is organized into three thoughts/concepts: Conflicting Ethics;

Professional Ethics, the Ethics of Professional Education and Professional Codes. Each section builds on the previous section to present a contextual picture. Criticisms of the structure of professional library ethics are offered throughout along with insight from professional ethics researchers.

\section{CONFLICTING ETHICS}

Conflicts between professional judgment and the business policies and decisions of institutions have existed throughout history. Consider these examples:

An urban hospital adopts new security measures in an effort to retain respected and well-established community physicians. The hospital's librarian arrives one morning to find workmen installing a new identification badge reader on the library door. As part of the security plan, the library has been designated for physician access only. Happy for the extra security measures but concerned that nurses, patients and other patrons identified in the library's mission might not be able to access the library's resources, the librarian calls a lead administrator for an explanation. The administrator refuses to discuss the issue, claiming the hospital's security plan takes precedence.

A hospital librarian notices a rise in the number of reference questions from physicians pertaining to drug/herbal medication interactions over the past year. After conferring with colleagues to identify authoritative, evidence-based resources addressing the subject, the librarian prepares a purchase order. The Medical Director abruptly revokes funding for the purchase, citing hospital policy pertaining to alternative therapies. The librarian reviews the policy and finds no components limiting the provision of information concerning alternative therapies. Rather, the policy details procedures for physicians to follow for handling alternative therapies which patients bring from home. The librarian shares this information with the Medical Director. Agitated, he begins a speech on the illegitimacy of alternative therapies and exclaims there will be no books, journals, newsletters, or other legitimate materials on any alternative therapies in the hospital's library.

When a librarian accepts a position, it is expected that the values and ethics of his employer are also accepted. Professionals, however, are trained to ground their ethics in a way which makes them "impervious to vacillations in philosophical fashions, as well as social, economic, or political change" (11). It is the professional's duty to function for the good of client's and ultimately the good of society as a whole. Given a librarian's unique knowledge, should not the institution permit the professional's ethics and values to prevail when making 
decisions related to his area of expertise?

Many employers recognize that their institutions ultimately benefit when professional employees are given the autonomy required to carry out their duties. In actual practice, however, the organizational design of the institution may reduce a professional's autonomy. There is often no clear line of authority in American hospitals. The medical staff and the hospital administration share a joint responsibility for decision making. Both entities strive to function in the interests of patient care, however, fiscal reality may lead to administrative decisions which conflict with the professional recommendations of the medical staff. When this occurs, federal, state, and local regulations and nationwide hospital standards support the medical staff (e.g., JCAHO, HCFA). Codified medical ethics, enforced by peers and by law, also defend their decisions. Dependent on physicians to operate, the hospital administration must seek solutions which satisfy the ethical requirements of the medical staff.

The legislation and codified ethics supporting physician's clinical decision-making is unique in the hospital setting. Nurses also benefit from legal regulations and standards requiring hospital administrators to provide the tools necessary to conduct their duties in the best interest of the patient. Unfortunately, the hospital librarian's authority is only weakly supported by JCAHO's second standard, Management of Information (12). The standard is vague in scope, with applicability to medical records and information systems as well as to the library.

When serious issues arise, institutions tend to hypnotize themselves into thinking their synopsis of the situation is correct and dismiss the professional as being too careful. This attitude has caused such tragedies in history as the Challenger explosion, when NASA, determined to keep the launch of the space shuttle on schedule, ignored engineers' recommendations against launching in cold weather (13). Without legislation or a clear system of ethical review by peers, hospital librarians are ill equipped to dispute poor decisions. If bureaucrats chose to disregard advice intended to prevent harm to clients or society overall, the professional has few options. A hospital library professional can either comply with the decision, protest, then accept the decision, or protest and submit a resignation. In the hospital library setting, the librarian's ability to execute the practical and ethical responsibilities of the profession is dependent on the bureaucratic nature of the institution. Unfortunately, "while we are prepared and inculcated to provide good libraries, the non-librarians who hired us can't define good except as cheap, or big, or even good enough" (13).

Are hospital libraries corporate libraries? Both are customer-driven, requiring flexibility in meeting the changing needs of the institutions they serve. Both require the establishment of close, personal relationships with clients and the ability to provide clients with information on demand. Both strive to offer value-added services to "ensure customer loyalty and to successfully compete with other internal and external information sources" (14).

Hospital libraries, however, serve a restricted population of users: physicians, nurses, and other employees of the hospital. Whether patients or the community utilize the hospital library's resources is dependent on the policy of the library and/or institution. Regardless, hospital libraries are distinctive from corporate libraries in that the information they provide affects the well-being of a third party: the patient and family members. Thus the tenets of intellectual freedom, information access, and confidentiality are of utmost importance in the hospital library. Placing the values of the institution above the ethics of the profession may seriously affect the patient's well-being $(7,8,9)$. For physicians to rely on current medical information to make sound clinical decisions, hospital librarians must function as independent professionals. 


\section{Professional Ethics}

Professionals differ from ordinary workers in a number of ways. Most importantly, professionals have received a considerable amount of knowledge and training with the expectation they will contribute some good to society. In return, society places its trust in the professional, giving them a high degree of autonomy to creatively use this expertise in a way which will benefit society as a whole. Society also bestows legal recognition and protection to certain groups of professionals, such as physicians (15). This permits patients to seek care with confidence that the cause and nature of their aliments will not be disclosed to the general public.

Pellegrino listed the characteristics of the relationship between professionals and those who seek their help (11). Such characteristics define the "internal morality" of a profession, dictating their grounding in a dynamic society. The client is the first distinguishing characteristic of the professional relationship. This individual is both dependent on the professional for help and vulnerable at his time of need. The inherent inequality of the professional relationship requires the client to trust the professional will not make poor use of his knowledge or use it in his own self interest. Thus, the professional relationship has a fiduciary character. The client must trust that the professional is using his knowledge in the client's best interest.

Professional knowledge is not wholly proprietary. Society asks professionals to hold knowledge in trust for those who need it. Professional knowledge holds a practical nature, helping others with certain fundamental human needs. The professional functions as the "final common pathway through which help and harm must pass" (11). With the client's trust, the professional's responsibility is to make the final decisions, actions, or recommendations. As a member of a self-regulating moral community, the professional also has the responsibility, with his community, to maintain both his client's and society's trust.

Maintenance of the community's trust or confidence is paramount for the professional. Without trust, the community will attribute little value to the professional's services. The societal principles which the community entrusted the professional to protect may irrevocably be damaged. Competence and character, then, are of substantial importance to the professional. Professional ethics set the standards for competence and character, identifying the moral responsibilities of the profession's members. Professional ethics also provide guidance, enabling the professional to sort through sensitive moral problems which have no definitive solutions.

Professional ethics are interdisciplinary in nature. To understand professional ethics an understanding of morality and a knowledge of the profession is necessary (16). Moral problems faced by professionals do not necessarily have correct solutions. The answer to one problem often has direct implications for another problem. Our perception of "the facts" is often the source of our moral disagreements. Our viewpoint on the consequences of a particular decision may differ from a colleague's. Our perceptions of human nature fundamentally vary.

Gert defines morality as a system. "The acceptability of answers that this system gives to any particular problem is affected by the acceptability of the answers that it gives to all other problems" (16). This system is public in nature and is justified once it is demonstrated that "all impartial rational persons would support the general moral system and could support any of the variations" (16). Behavior is guided and evaluated by the moral system. Individuals understand the acceptable, unacceptable and expected actions required by the system. It is not irrational to accept a moral system and to be guided by it. Moral theories (deontological, consequentialist, etc.) provide explanation and justification of moral systems. Such theories indicate which actions 
are required by morality, or the moral system, and which actions are encouraged by it. They also demonstrate the relationship of morality to social institutions and practices, including legislation and professional roles.

When moral systems are studied, the inconsistencies in individual's moral actions become apparent. After weighing all of the morally relevant facts, the individual may make a decision which conflicts with a previous moral decision. For example, the writers of the U.S. Declaration of Independence in 1776 declared all men to be created equal. States, however, denied women and minorities the moral right to vote or hold office for years. During the Women's Suffrage and Civil Rights movements of the 1920s and 1960s respectively, individuals recognized that moral judgments conflicted with the community's moral system. The community's moral system could no longer be justified.

There are five harms all rational persons need to avoid to remain moral in our present society:

- Do not kill (or cause permanent loss of consciousness);

- Do not cause pain (mental or physical);

- Do not disable (or cause loss of ability);

- Do not deprive of freedom (or opportunity); and

- Do not deprive of pleasure.

An additional five actions should be avoided to protect others from harm or suffering:

- Do not deceive;

- Honor your promises;

- Do not cheat;

- Do not disobey the law; and

Do your duty, or what is required of you by your role in society (16).

Common sense dictates most of these rules, which outline morality on a basic level. Professions must determine what constitutes harm in the context of their work. The ALA Code of Ethics asserts that librarians will protect the principles of intellectual freedom on behalf of society (3). By denouncing censorship, the ALA membership recognizes that librarians, as professionals, hold a position which may cause potential harm. A librarian's decisions may promote or hinder society's open exchange of ideas. The MLA Code of Ethics for Health Sciences Librarianship specifically states the health sciences librarian's responsibility to "promote access to health information for all" and maintain "conditions of freedom of inquiry, thought, and expression that facilitate informed health care decisions" (2). Thus librarians, whether in the public or hospital setting, have the ethical duty and responsibility, to provide fair, impartial access to information.

Recent literature on professional ethics has traced public disenchantment with the professions to society's perception that professionals have abandoned their social and ethical responsibilities. Lured by commercial, competitive, and government forces, self-interest has hindered professional's ability to work for the good of the communities they serve $(11,17,18,19)$. This perception has not resulted from lack of knowledge of ethical duties but rather lack of compliance $(11,17,19)$.

McDowell identifies excuses professionals use to avoid responsibility, justify exception, 
and explain the reasons for underlying unethical behavior (19). Most ethical lapses, he explains, occur when professionals avoid making hard decisions. For example, a hospital librarian may claim ignorance after releasing patron records to a concerned family member investigating a medical incident. The invalidity of the professional's claim is exposed as a professional is required to know and understand the ethical obligations of the profession. A hospital librarian may also transfer responsibility for the substandard provision of information to administrators or other parties, citing lack of funds or lack of staff for assistance. Such actions illustrate the librarian's inability to avoid the temptation to "evade or escape responsibility for injuries their professional activities cause a client or third parties" (19).

The hospital librarian may also succumb to "irresistible pressure." This is the perception that the professional is powerless to act ethically or that the professional cannot justify the cost associated with the ethical decision. The purpose of professional education is to prepare an individual to function in an environment where the pressure to act unethically is strong. Thus when administrators adopt policies which contradict the library profession's values, librarians must speak up and act appropriately.

While all individuals are fallible, it the professional community's responsibility to determine which degree of fallibility is acceptable for it's members. A professional's excuses may only be evaluated by peers and by the law. The professional community and/or a court may reinterpret ethical lapses in conduct as negligence. Therefore professionals must be prepared to deal with the ethical pressures they encounter in day to day activities.

\section{ETHICS, PROFESSIONAL EDUCATION AND PROFESSIONAL CODES}

Professional education plays a significant role in preparing professionals to handle the ethical pressures they will encounter in their daily activities. A profession's membership defines morality and typically captures it in written codes. Educators rely on these ethical codes and case studies to teach students the mandatory virtues required of all individuals practicing in their particular profession. Students learn that while ethical codes define their profession's authority, they also serve a variety of other purposes.

Professional codes of ethics mainly function to provide members with an interpretation of the moral ideals to which the profession aspires to adhere. Such codes may indicate the minimum standards of competence members must maintain or establish guidelines for fair competition among members offering similar services. They may serve to educate the public on what to expect from the profession or offer the public confidence that the professional services they are purchasing are of considerable quality. Professional codes of ethics establish trust between the professional and the public he or she serves, enabling him to perform duties which may contradict the mainstream philosophical, social or political environment. Codes also support professionals to resist pressure from employers or society to perform unethical duties $(16,20)$.

Many thinkers, however, criticize professional codes of ethics as being veiled public relations tools designed to enhance the profession's status $(16,21)$. Could their authors merely be stating the obvious? Marco writes of his dismay with the literature on library ethics stating "Much of what is offered as guidance to ethical conduct is redundant to rules of conduct that apply to those outside as well as within the profession" (22). Indeed the American Library Association's Code of Ethics compels librarians to treat their co-workers and other colleagues with "respect, fairness, and good faith"; to not advance private interests at the expense of their employer; to maintain separation between personal and professional beliefs; and to maintain 
competence. These are ideals which could apply to any profession (3). The Medical Library Association's Code of Ethics for Health Sciences Librarianship more successfully conveys a sense of uniqueness, yet most of its statements are task oriented (2). This is "redundant to the definition of the profession" (22).

To formulate a honorable code of professional ethics which rises above its public relations function, Gert states that a profession must examine its interpretation of the various moral rules. It then must identify the specific duties required of the profession to achieve their defined moral ideals (16). Essentials for most ethical codes include high standards for competence; confidentiality; maintenance of the public trust; and a means for enforcement of the ethical code. Without a means for enforcement, ethical codes lack authority (23-24). The professional community's ability to sanction members who violate principles of the profession is then limited. The poor or unethical decisions of a few members may damage the profession's ability to maintain the public's faith and trust and the profession's ability to defend its actions against pressures and outside interests is compromised.

Library codes of ethics then are weak and ill-conceived, with vaguely defined ethical principles and no means of enforcement. Our literature reflects the profession's struggle with addressing its ethical principles as authors often write "on a more personal level, frequently incorporating [their] own values and ethical concepts" (25). Librarians avoid the in-depth exploration of professional ethics. Crawford reasons librarians fear detailed discussion of ethics because as a profession, we may feel unqualified to supervise the morals of others; we hide behind the pressures of our work; we shy away from confrontation; or we are reluctant to change our routines (20). The library profession indeed has difficulty addressing professional ethics. As a result, librarians find it difficult to educate employers (whether they are hospitals, corporations or public agencies) on professional ethical values, inviting conflict, inconsistent action, and skirting responsibilities.

Is a code of professional ethics, however, a cure for our ethical difficulties? Koster asserts that ethical codes are just not useful as it is nearly impossible to apply them to the real-life situations they are intended to address (26). Rarely, can an individual resolve an ethical issue using an ethical code alone. There are too many complexities and gray areas involved. Balnaves points to Benson Y. Landis' 1927 research of over 200 professional and business organizations with ethical codes which found that most ethical codes resulted from conflicts between a professional, his client, his employer, or his colleagues. Codes were also formulated to avoid regulation by the government or an employer (21). Librarian's ethical codes, while intended to support the librarian in resolving conflicts, have failed as a result of their conservatism. To claim authority as a professional, a mechanism for peer-enforcement of library ethics is needed.

Reliance on ethical codes and case studies to teach library students professional ethics is flawed just as the profession's ethical codes are flawed. Case studies are useful to introduce the ethical issues librarians face yet as "each writer approaches each scenario from a slightly different perspective, it is difficult to draw any guidelines or conclusions" (26). This leads students to rely on the ethical codes which cannot, by their very nature, address the context of the ethical situation. Perhaps the teaching of library professional ethics should be more interdisciplinary in nature with educators exploring the thoughts of modern and classical philosophers on virtue, morals, and character in more detail. The scrutiny of various librarians' interpretations of moral rules pertinent to the profession should be encouraged. Since ethics form the basis from which professions draw their authority, library educators must: (a) encourage in depth discussions on ethics in library science courses; and (b) either highly recommend or 
require that library science students take a library ethics class. In return, library educators and professionals must work to better define the profession's moral rules and develop a system of peer review to enhance the authority of library professionals in the corporate, hospital, academic, and public library settings.

\section{CONCLUSION}

Perhaps White's opinion that librarians have split personalities is correct. Our one personality identifies with professional colleagues and the other identifies with the local team or organization. "Whether we are academic, public, or special librarians," writes White, "we become members of the team, and even when we know the results for our users are unsatisfactory, we abandon at the local level our nationally stacked ethical positions" (13). Such a mentality seriously damages the professional authority of hospital librarians. To maintain the faith, trust, and support of physicians, administrators, and the community, hospital librarians must act consistently.

When conflicts between professional judgement and the policies of the institution occur, hospital librarians must demonstrate their authority as a professional. They must disclose their ethical concerns and work with administrators to find an acceptable solution. Librarians cannot ignore the ethical obligations society has entrusted to the profession. Hospital librarians must act in accordance with the ethical values adopted by the health sciences library profession. Without a mechanism to enforce adherence to professional ethics, hospital librarians must rely on personal integrity. If an administrator demands an action contrary to professional ethical standards, the hospital librarian must be prepared to refuse and offer explanation. The codes, while flawed, voice our authority to protect intellectual freedom on behalf of society.

An agenda is needed for the library profession as a whole to discuss and better define the moral rules which form the foundation of our professional ethics. Discussion of methods and strategies to enforce the professions ethical standards is also important. It is duty of hospital librarians to function for the collective good of society. Let hospital librarians embrace this responsibility as they serve their clientele.

\section{REFERENCES}

1. United Nations. Universal declaration of human rights. 1948; http://www.un. org/Overview/rights.html (1999 August 5).

2. Medical Library Association. Code of ethics for health sciences librarianship. 1994 http://www.mlanet.org/about/ethics.htm (2000 February 14).

3. American Library Association. Code of ethics. 1995; http://www.ala.org/ alaorg/oif/codeofethics.pdf (2000 February 14).

4. American Library Association. The freedom to read. 1991; http://www.ala.org/ alaorg/oif/freedomtoread.pdf (2000 February 14).

5. American Library Association. Library bill of rights. 1996; http://www.ala.org/ alaorg/oif/librarybillofrights.pdf (2000 February 14).

6. Holst R.Hospital libraries in perspective. Bull Med Lib Assoc 1991;79(1):1-8.

7. Marshall JG. The impact of the hospital library on clinical decision making, the Rochester study. Bull Med Lib Assoc 1992;80(2):169-78.

8. Klein MS, Ross FV, Adams DL, Gilbert CM. Effect of online literature searching on length of stay and patient care costs. Acad Med 1994 69(6): 489-95.

9. Veenstra R. Clinical medical librarian impact on patient care : a one-year analysis. Bull Med Lib Assoc 1992 80(1): 19-22. 
10. Preer J. Special ethics for special librarians? Spec Libr 1991;82(Winter):12-18.

11. Pellegrino E. Character, virtue, and self-interest in the ethics of the medical profession: Part II: Toward the restoration of virtue ethics. Ref Serv Rev 1994;22(2):41-52.

12. Joint Commission on Accreditation of Healthcare Organizations. Comprehensive accreditation manual for hospitals. Oakbrook, Ill: The Joint Commission; 1998.

13. White H. The conflict between professional and organizational loyalty. Libr J 1991 May 15;116:59-60.

14. Jaiko P. Hospital and corporate information services: introducing a new column. Med Ref Serv Q 1992;11(1):63-6.

15. Alexandra A, Miller S. Needs, moral self-consciousness, and professional roles. Prof Ethics 1996;5:43-61.

16. Gert B. Morality, moral theory, and applied and professional ethics. Prof Ethics 1992;1:5-24.

17. Pellegrino E. Character, virtue, and self-interest in the ethics of the medical profession: Part I: The erosion of virtue and the rise of self-interest. Ref Serv Rev 1994;22(2):29-44, 55.

18. May L. The socially responsive self: social theory and professional ethics. Chicago, IL: The University of Chicago Press; 1996.

19. McDowell B. The excuses that make professional ethics irrelevant. Prof Ethics 1994;3:157-170.

20. Martin M. Personal ideals in professional ethics. Prof Ethics 1996;5:3-27.

21. Balnaves J. "Ethics and Librarianship." In: Gorman GE, ed. The education and training of information professionals: comparative and international perspectives. Metuchen, NJ: the Scarecrow Press, Inc.; 1990. p.227245.

22. Marco G. Ethics for librarians: a narrow view. J Libr Info Sci 1996 March; 28:33-7.

23. Hill M. Facing up to dilemmas: conflicting ethics and the modern information professional. Aslib Proc 1998;50(4):71-8.

24. Crawford H. In search of an ethic of medical librarianship. Bull Med Lib Assoc 1978;66(3):331-7.

25. Wood MS. Public service ethics in health sciences libraries. Libr Trends 1991;40(Fall):244-57.

26. Koster G. Ethics in reference service: codes, case studies, or values? Ref Serv Rev 199;20(1):71-80. 